the biggest problems in these sections about the pre-war period are due to Wigner's obtrusive modesty. The overly shy description of what he did in those years gives no clue that it was work of Nobel-prize calibre.

The book really comes alive again with the chapters dealing with Wigner's involvement in the Manhattan Project. These are quite excellent. They will be particularly appreciated by all those unacquainted with the workings of bureaucracy, especially if they can sense how much it can eventually achieve. The remarks about General Groves are splendid, as are the sketches of Fermi and other scientists. Wigner is a little less self-effacing about his own contribution here, but even so I would have liked to learn more about it. On the other hand, Wigner's ruminations about the work that was going on in Germany on the atomic bomb are generous and thought-provoking, as are his revealing comments on Oppenheimer.

The post-war period is described in an illuminating way. Wigner could come to terms with a bureaucracy driven by the pressures of war, but not with one in peacetime. The return to Princeton was a success, which enabled him to do much external work in which he evidently found some satisfaction and some frustration. He is at his most engagingly frank when talking about the Nobel prize and the pleasure it gave him.

Perhaps the most revealing paragraphs relate to his fellow Hungarians Szilard, von Neumann and Teller. His tortured love-hate relationship with Szilard evidently troubled him greatly, and the honesty of his remarks is transparent. His admiration for von Neumann and his grief for his early death come through very well, but inevitably it is his comments on that very controversial character, Teller, that hold most interest. Wigner's loyalty to Teller is total, but he manages to combine it with his admiration for Oppenheimer's leadership at Los Alamos in a frank and indeed engaging manner. What informed Wigner's Hungarian group was a permanent deep hatred of communism (perhaps because of the experience of Bela Kun?), never ameliorated by the slim hope that so many of us entertained for so many years that something less obnoxious, even if still ostensibly communist, might eventually emerge in Eastern Europe.

This brief description cannot possibly do justice to an important and very worthwhile book. My disappointments, which I have expressed freely, should not discourage anybody from reading it. In the interests of science I wish this book every success.

Sir Hermann Bondi is at Churchill College, Cambridge CD3 ODS, UK.

\section{From thought to expression}

\section{S. S. Schweber}

Genius: Richard Feynman and Modern Physics. By James Gleick. Pantheon/ Little, Brown: 1992. Pp. 532. \$27.50, £18.99.

SCIENTIFIC communities usually seek to convey the importance and the history of their discipline through the lives of their outstanding practitioners - individuals whose very creativity renders them unlikely to be the best representatives of their worlds. Physicists have principally chosen theorists as their heroic figures (Newton, Maxwell, Einstein, Planck, Bohr, Dirac, Pauli) or experimenters who left their mark in both experimenta-

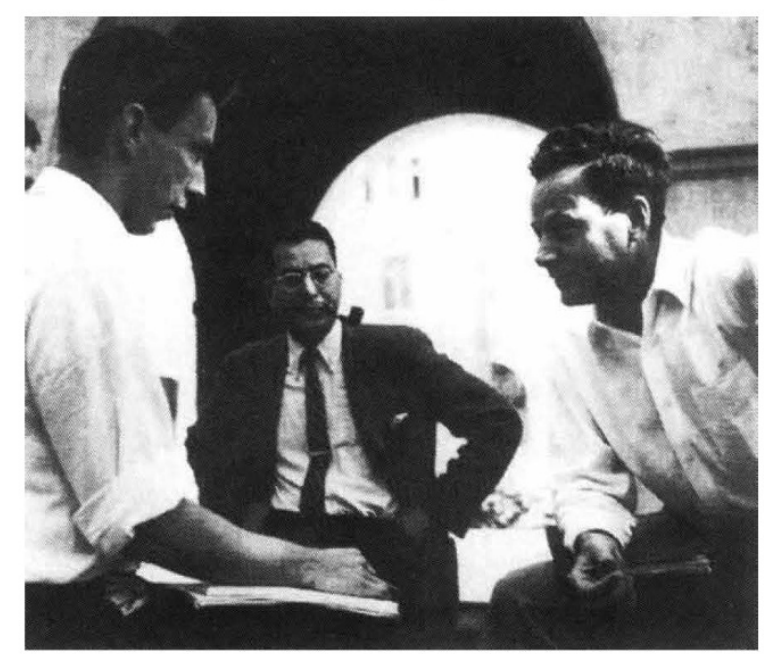

Talking it through - Feynman chats with a student as Murray Gell-Mann looks on.

tion and theory (J. J. Thomson, Rutherford, Fermi), thereby emphasizing the ties of the discipline to the tradition of natural philosophy. The cult idols are the reification of the aspirations and myths of the community and the embodiments of its cherished values. (And just as what is not said can be as revealing as what is, those left out of the hall of fame disclose much about the community.)

Einstein and Bohr, and to a lesser degree Planck and Rutherford, are the heroes from the period before the Second World War. They have come to stand for the advances ushered in by relativity and quantum mechanics. Dirac embodies the 'genius' of the quantummechanical revolution and is the prophet who pointed the way in the synthesis of relativity and quantum mechanics. And Landau and Feynman have become the heroes of the post-quantummechanical era. Both were enormously creative and innovative and made lasting conceptual contributions (a necessary condition for admission to the pantheon). Both encompassed all of physics, and could therefore be taken as representing the unity of the enterprise, resisting the fragmentation of the discipline and the attendant specialization. Although at various times they set and dominated the intellectual agenda of the community, they were often also the main challengers of the ruling orthodoxies. They were thus simultaneously insiders and outsiders. Similarly, both were unusual in their social behaviour - and the community was willing to condone in them conduct that would not be acceptable in society at large. And after the Second World War, during an epoch shaped by the Cold War, polarized by concerns about national security and dominated by military-industrial complexes, both men consciously distanced themselves from the conflict. They could therefore be seen as 'pure scientists' transcending national rivalries.

There is so far no satisfactory intellectual and psychological portrait of Landau or an adequate account of his life. But with James Gleick's Genius we now have a superb biography of Feynman. The book is a moving, beautifully written, literate and perceptive account of Feynman's life, which Gleick sets sensitively in the context of the physics community, of the larger culture and of the times.

We get a feel for life in the Jewish community of Far Rockaway during the 1920 s. We learn what it was like to be an undergraduate at the Massachusetts Institute of Technology during the 1930s. We become privy to the extensive antisemitism in the élite American universities at that time; to life at Los Alamos during the Second World War; to the politics of universities after the war; to the dynamics of selecting and receiving Nobel prizes; to the world of NASA stripped of its public-relations gloss, and the behind-the-scenes activities of the presidential commission investigating the Challenger disaster.

As readers of Gleick's earlier book Chaos know, this author has a gift for capturing the atmosphere of a community and for providing sharply focused, perceptive sketches of its principal characters. We get to know Schwinger, Bethe, Weisskopf, Dyson, Gell-Mann and some of the other leading theorists, and, while doing so, we learn a great deal about the sociology of the theoretical physics community of the time and 
the competitive dynamics that animated it. The book also contains lucid accounts of many of the advances in theoretical physics since the middle of this century - Feynman diagrams, renormalization theory, the explanation of the superfluidity of liquid helium, partons and quarks, the standard model -- advances to which Feynman made important, fundamental contributions. Gleick's accomplishment in this area is uncommon because he is not a scientist by training, yet his presentation of the science is accurate and readily accessible to the general reader.

Gleick never met Feynman. His knowledge of his subject stems from interviews with members of Feynman's family, with colleagues and former students, and with friends dating back to Feynman's highschool and college days. He read and listened to taped interviews with Feynman that various historians had made earlier, in particular the extensive and remarkable interviews that Charles Weiner recorded in the late $1960 \mathrm{~s}$ and mid-1970s. He studied videotapes of Feynman's lectures and television programmes, and pored over some 25 cartons of papers, notes and correspondence that Feynman had deposited in the archives of the California Institute of Technology. It is clear that Feynman was unusually gifted, highly original and inventive. But the vivid portrait that Gleick draws would not have been possible without access to the personal letters that Feynman had kept in his house. Gweneth, Feynman's wife, allowed Gleick to read the correspondence between Feynman and his parents, between Feynman and his first wife, Arline, and letters to Feynman from lovers and personal friends.

Feynman's relationship with Arline his first girlfriend, his first and perhaps his only true love, and his first wife shaped his subsequent life. Arline was diagnosed as having lymphatic tuberculosis while Feynman was at MIT. Despite the strenuous objections of his parents, the two got married before Feynman went to Los Alamos early in 1943. Throughout his stay there, Arline was in a hospital in Albuquerque and she died shortly before Trinity in 1945. Feynman never recovered from the loss, seemingly arriving at the conviction that he would never again be fulfilled in love. Two years after Arline died, Feynman - the supreme rationalist - wrote her a heart-rending love letter. His subsequent interactions with women were always affected by the scars incurred by the loss - until his marriage to Gweneth, the emptiness and yearning were filled by one-night stands and tempestuous, destructive love affairs. Similarly, in physics he came to accept human limitations: unification and, in particular, a theory of

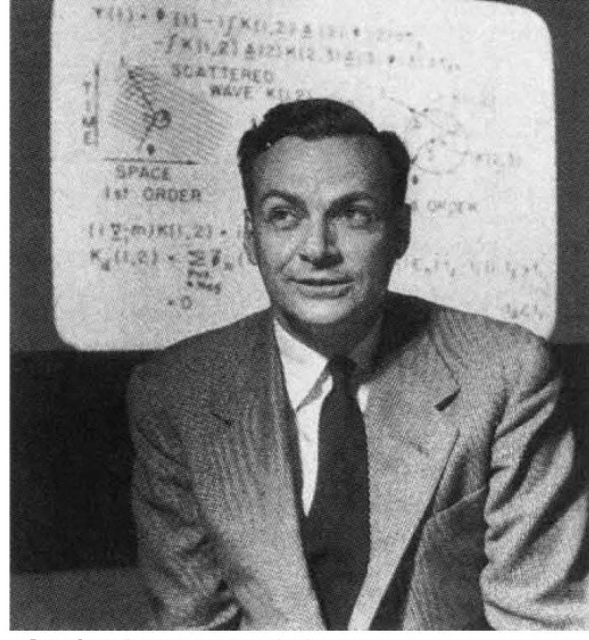

\section{Genlus born or made?}

everything were, in his view, fantasies with which the community deluded itself. Physics consisted of a set of algorithms that answered with a high degree of certainty questions of the form: 'If I do this, what will happen?' Feynman searched for such algorithms with extraordinary courage and unshakeable integrity.

Gleick is captivated by Feynman's "genius". (Who wouldn't be?) At times he seems obsessed by the notion of genius and by the search for what constitutes its possession. He fails to find the holy grail, but does make clear that to understand Feynman one has to apprehend his peculiar connection to his social world and his distinctive intellectual relationship to the scientific community in general and the physics community in particular. In intellectual matters Feynman was able to straddle the gulf between self and community. He could adhere to many of the tenets, assumptions, forms of thought and styles of reasoning that characterized the theoretical physics of his day while also transcending their limitations. One aspect of Feynman's genius was that he could make clear what was obscure to most of his contemporaries. His doctoral dissertation and his 1947 Reviews of Modern Physics article that presented his path-integral formulation of nonrelativistic quantum mechanics helped to clarify in a striking manner the assumptions that underlie the usual quantummechanical description of the dynamics of microscopic entities. And he did this in the very act of transcending the usual formulation with a startling innovation. It may well be that his reformulation of quantum mechanics and his "integral over paths' will turn out to be his most profound and enduring contributions. They have deepened considerably our understanding of quantum mechanics and have greatly extended the systems that can be quantized. And judging from the work of Michael Atyah and Ed
Witten, Feynman's path integral has already substantially enriched mathematics and provided new insights into spaces of infinite dimensions.

Early on. Feynman also learned to walk the tightrope between his own psychological needs and the requirements of belonging to a community. He came to accept and appreciate the fact that the act of creation was for him also an act of consummate isolation.

The creative act depends on private visions and solitary constructions and always draws on the legacy and the resources of the community, be it in the arts, literature, technology or the sciences. We call people geniuses when their ability to synthesize thesc communal resources overwhelms us; and if the synthesis happens to result in a startling outcome, as in the case of Feynman, we are amazed and awe-struck. But by creating a category of people we label as geniuses, we are on a slippery slope that may lead us to believe that there is an innate quality attached to the attribution, when instead we should focus on its social and cultural dimensions. Rather than Genius, I would have called this impressive book The Remarkable Life and Science of Richard Feynman.

S. S. Schweber is in the Department of Physics, Brandeis University, Waltham, Massachusetts 02254. USA.

\section{Mathematics in the mind}

\section{Michael Berry}

Pi in the Sky: Counting, Thinking, and Being. By John D. Barrow. Oxford University Press: 1992. Pp. 317. £14.95, $\$ 25$.

MY son, a musical beginner, keeps getting confused about intervals: asked to play a fourth, he delivers a fifth. I suppose this is a widespread confusion, whose origin might lie in the absence of zero from musical notation. Intervals $(n)$ therefore obey not the addition rule of ordinary arithmetic but $(\mathrm{n})+(\mathrm{m})=(\mathrm{n}+\mathrm{m}-1)$ : a second plus a second equals a third. Realizing this, we suddenly see how deeply we have interiorized the conventions of elementary mathematics. One of John Barrow's aims is to trace the origins of these counting conventions in human (and animal) societies. This is part of a far more ambitious programme: understanding the meaning of mathematics and the role it plays in science.

By profession, Barrow is an astronomer and physicist, and the mainspring NATURE - VOL 360 - 26 NOVEMBER 1992 